\title{
Real-time monitoring instrument designed for the deformation and sliding period of colluvial landslides
}

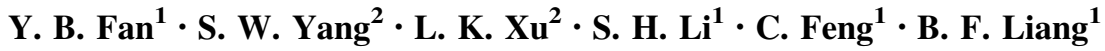

Received: 29 October 2015/Accepted: 8 January 2016/Published online: 25 January 2016

(C) Springer-Verlag Berlin Heidelberg 2016

\begin{abstract}
A real-time monitoring instrument for colluvial landslides that can capture horizontal displacement during the deformation period of the slope, deep dislocation displacement, accurate depth of the slip surface, and sliding direction during the initial sliding period has been developed. The horizontal displacement monitoring system is a monitoring apparatus assembled in an array based on the MEMS (Micro-Electro-Mechanical System). Horizontal displacement is obtained by integration of the $\mathrm{X}$ - and Y-direction angles along the drilling direction, and the sliding direction is simultaneously measured via vector composition of the X- and Y-direction angles obtained from the MEMS sensor. Deep dislocation displacement is calculated based on the relative displacement between the base point embedded in the bedrock and measuring point above the sliding surface, and measurement of relative displacement is executed by an angular displacement sensor fixed on top of the inclinometer tube. The accurate depth measurement of the slip surface is transferred to the judgment about the on-off state of the signal wire. Based on the long-term monitoring of the Yu Jiaba landslide at the Three George dams, an open-pit mine in Inner Mongolia province, and an Anshan open-pit mine, the results reveal that the reliability of the instrument is very high. High accuracy, ability to capture the entire landslide
\end{abstract}

Y. B. Fan

ybfan@imech.ac.cn

1 Key Laboratory for Mechanics in Fluid Solid Coupling Systems, Institute of Mechanics, Chinese Academy of Sciences, Beijing 100190, People's Republic of China

2 Beijing Excellence Longitude and Latitude Measuring and Control Co., Ltd, Beijing 100190, People's Republic of China process, large deformation monitoring, autonomous data collection, and reusable characteristics could be implemented.

Keywords Real-time monitoring instrument · Colluvial landslides · Horizontal displacement - Deep dislocation displacement $\cdot$ Accurate depth of the slip surface $\cdot$ Sliding direction

\section{Introduction}

In many parts of the world, landslides can impose a severe threat to life, property, and infrastructures as well as large financial costs on society (Angeli et al. 2000; Lan et al. 2004). In order to maintain an adequate level of safety in situations where human life, property, or infrastructures are exposed, optimal risk management requires warning systems based on real-time acquisition of reliable data from permanent monitoring instruments (Angeli et al. 2000; Tarchi et al. 2003; Carlo Colesanti et al. 2003; Hu et al. 2015; Tang et al. 2015).

The assessment of landslide behavior is usually undertaken via real-time monitoring (Liu et al. 2004; Yin et al. 2010; Tuccimei et al. 2015; Kopf et al. 2015; Zhao et al. 2015). A method is suggested (Crosta and Agliardi 2003) to forecast slope failures and to assess alert velocity thresholds using monitoring data. Deep and superficial displacements have been measured (Di Maio et al. 2013) since 2005 in a slow active landslide that occurred in a stiff clay formation of the Italian Southern Apennines. Over the past few years, monitoring systems have become powerful tools for understanding the kinematic aspects of mass movements and have enabled superior analysis and interpretation. 
Colluvial landslides exhibit great variability from typological, geometrical, and kinematic standpoints. This variability results from the forming process. Each colluvial landslide is therefore characterized according to its development, and the development type determines the kind of sensors that should be set up, the number and location of measurement points, and the sampling frequency of parameters.

In order to obtain reliable results, a monitoring instrument needs to include various practical technologies that can provide consistent observations under a wide range of operating conditions. Thus, the stability and reliability of the monitoring instrument are critical. This article presents the characteristics, application of the instrument, and triggering mechanism of the slide through comprehensive analysis of several long-term observational data sets.

\section{Methods and technologies for the monitoring of colluvial landslides}

A general overview of the methods for measuring colluvial landslide displacements has been used (Table 1) to track the superficial movements of unstable slopes
(Pincent and Blondeau, 1978; Schuster and Krizek 1978; Krauter 1988; Mikkelsen 1996). Conventional geodetic techniques (e.g., triangulation and tacheometry) and extensometry techniques (Angeli et al. 2000) are still the most commonly used because they can provide an accuracy of a few millimeters on short baselines of less than a kilometer. Short-base extensometers, precision tape, fixed wire extensometers, rods, leveling vernier poles, or fissure meters have been used to record the opening of cracks or the distance variations between "moving" points (Gulla et al. 1988). Tacheometric levels, theodolites, electronic distance meters, and geodetic stations make it possible to record continuous slope displacements by providing the coordinates of control points and their changes (Ashkenazi et al. 1980). Terrestrial or aerial stereo-photogrammetry can provide the coordinates of "moving" points, contour maps, and the cross-sections along unstable slopes (Ballantyne et al. 1988; Chandler and Moore 1989; Oka 1998). Realtime measuring with ground-based radar (Dick et al. 2014) is a remote sensing technology that uses phasechange interferometry to measure the surface deformation of a slope over time. A comprehensive summary of the main methods, typical range, and accuracy are shown

Table 1 Overview and characteristics of the main methods used in monitoring surface displacements and their accuracy

\begin{tabular}{|c|c|c|c|c|}
\hline Method & Use & Results & Typical range & Typical accuracy \\
\hline Micrometer screw level & Angular displacement & da & $0.1 \mathrm{rad}$ & $4.10^{-4} \mathrm{rad}$ \\
\hline Fissurometer & Differential movement of compartments & $\mathrm{dD}$ & $<20 \mathrm{~mm}$ & $\pm 0.1 \mathrm{~mm}$ \\
\hline Leveling vernier pole & Opening of small cracks & $\mathrm{dD}$ & $<200 \mathrm{~mm}$ & $\pm 0.5 \mathrm{~mm}$ \\
\hline Short-base extensometer & Opening of cracks & $\mathrm{dD}$ & $25-450 \mathrm{~mm}$ & $\pm 0.1 \mathrm{~mm}$ \\
\hline Invar distance-meter & Displacements of moving targets & $\mathrm{dD}$ & Up to $40 \mathrm{~m}$ & $\pm 0.1 \mathrm{~mm}$ \\
\hline Wire extensometer & Displacements of moving targets & $\mathrm{dD}$ & Up to $100 \mathrm{~m}$ & $\pm 0.5 \mathrm{~mm}$ \\
\hline Tacheometric level & Variation of altitude & $\mathrm{dZ}$ & Variable & $20 \mathrm{~mm}$ \\
\hline GPS & Displacements of moving targets & $d X, d Y, d Z$ & Baseline $<20 \mathrm{~km}$ & $1-2 \mathrm{~mm}$ \\
\hline Terrestrial photogrammetry & Displacements of moving targets & $d X, d Y, d Z$ & $<200 \mathrm{~m}$ & $40 \mathrm{~mm}$ \\
\hline Aerial photogrammetry & Displacements of moving targets & $d X, d Y, d Z$ & Hflight $<500 \mathrm{~m}$ & $100 \mathrm{~mm}$ \\
\hline Radar interferometry INSAR $^{\mathrm{a}}$ & DEM comparison & $d X, d Y, d Z$ & Variable & $3-5 \mathrm{~mm}$ \\
\hline Precision tape & Opening of cracks & $\mathrm{dD}$ & $<30 \mathrm{~m}$ & $0.5 \mathrm{~mm} / 30 \mathrm{~m}$ \\
\hline Fixed wire extensometer & Opening of cracks & $\mathrm{dD}$ & $<10-80 \mathrm{~m}$ & $0.3 \mathrm{~mm} / 30 \mathrm{~m}$ \\
\hline Rod for crack opening & Opening of cracks & $\mathrm{dD}$ & $<5 \mathrm{~m}$ & $0.5 \mathrm{~mm}$ \\
\hline Offsets from baseline & Opening of cracks & $\mathrm{dH}, \mathrm{dV}$ & $<100 \mathrm{~m}$ & $0.5-3 \mathrm{~mm}$ \\
\hline Surveying triangulation & Displacements of moving targets & $d X, d Y, d Z$ & $<300-1000 \mathrm{~m}$ & $5-10 \mathrm{~mm}$ \\
\hline Surveying traverses & Displacements of moving targets & $d X, d Y, d Z$ & Variable & $5-10 \mathrm{~mm}$ \\
\hline Geometrical leveling & Variation of altitude & $\mathrm{dZ}$ & Variable & $2-5 \mathrm{~mm} / \mathrm{km}$ \\
\hline Precise geometrical leveling & Variation of altitude & $\mathrm{dZ}$ & Variable & $0.2-1 \mathrm{~mm} / \mathrm{km}$ \\
\hline Clinometer & Angular displacement & da & $\pm 10^{\circ}$ & $0.01-0.1^{\circ}$ \\
\hline Electrooptic distance-meter & Displacements of moving targets & $\mathrm{dD}$ & $1-10 \mathrm{~km}$ & $7 \mathrm{~mm} \pm 1-5 \mathrm{ppm}^{\mathrm{b}}$ \\
\hline Geodetic station & Displacements of moving targets & $d X, d Y, d Z$ & $1-10 \mathrm{~km}$ & $3 \mathrm{~mm} \pm 1-5 \mathrm{ppm}$ \\
\hline
\end{tabular}

${ }^{a}$ Interferometric Synthetic Aperture Radar

b 1 ppm indicates one part per million or one additional millimeter per kilometer of measured line 
in Table 1. The presentation of these methods should not suggest the exclusion of alternatives.

\section{The introduction of the real-time monitoring instruments}

Among the parameters that can reflect the behavior of a mass movement and forecast its short-term evolution, the horizontal displacement at different depths, deep dislocation displacement, depth of the slip surface, and sliding direction of the slope are particularly significant for different periods of the colluvial landslides. Although monitoring technologies cannot provide a variety of information on a limited number of points within the landslide area of concern, the displacement and direction data of a measuring point are adequate for the initial judgment of the landslides (Keaton and DeGraff 1996; Mikkelsen 1996; Allaway et al. 1998; Coe et al. 2000; Gili et al. 2000; Angeli et al. 2000; Ulusay 2015).

An instrument that monitors the deep dislocation displacement that was initially executed by Meng (Meng et al. 2007) has been applied in Sichuan, Hubei, and Chongqing provinces. A large amount of monitoring data about the deep dislocation displacement has been obtained during the last 10 years, and the reliability of the instrument has been simultaneously verified.

Deep dislocation displacement monitoring of the slip surface is typically obtained from the advised method in "the device about measuring the depth of slip surface and deep dislocation displacement" patent (Meng et al. 2007) issued in 2007. The device includes an angular displacement sensor and a bracket with a reel, steel wire, and inclinometer tube. The steel wire passes through the cambered cavity and connects with the reel above and the base point below. The base point is generally within the bedrock, and the measuring points have 1-m intervals upwards from the base point. When deep dislocation displacement occurs, the inclinometer tube is cut off, and the steel wire is pulled along the sliding direction. The length variation of the steel wire is captured by the angular displacement sensor on top of the inclinometer tube. The accuracy of deep dislocation displacement measuring is $0.1 \mathrm{~mm}$, and the measuring range includes 1,3 , and $5 \mathrm{~m}$. This measuring range perfectly meets the demand of large deformation measurement for colluvial landslides. However, the depth measuring of the slip surface is calculated via two measuring points, so the accuracy of the slip surface depth is subject to the interval of the measuring points.

Besides the deep dislocation displacement monitoring, the depth of the slip surface is equally crucial during the stability evaluation of landslide disasters. The multi-point displacement meter and advised methods above are the general approaches. The measuring range of the first method is limited because the number of anchor heads is only six. Relative displacement monitoring between the base point embedded in the bedrock and the measuring point above the slip surface in the second method has a large measuring range and high accuracy characteristics, but it is subject to the interval of the measuring points.

Measuring instruments of the depth of the slip surface herein include the inclinometer tube, angular transducer, photoelectric switch, pressure regulation screw, fixed pulley, gear box motor, scientific data loggers, sliding rheostat, electrical resistance, ampere meter, signal wire, plastic ring, and anchoring device. The signal wire passes through the cambered cavity and is fixed at the base point via the plastic ring and anchoring device. When the signal wire is cut off at the sliding surface, the electric current value exhibits a large change. Scientific data loggers can then transmit this cutoff signal to the gear box motor to elevate the signal wire. When the end of the signal wire passes through the photoelectric switch, it sends a signal that stops the gear box motor. Ultimately, the length of the signal wire can be calculated by the angular transducer with the encoder.

Before the sliding period, horizontal displacement at different depths has likely occurred. Therefore, monitoring horizontal displacement at different depths is equally important. The horizontal displacement monitoring system includes the MEMS tilt angle sensor (Alves et al. 2012), positioned ribbing, spring bracket, joints, measuring tube, scientific data loggers, and signal wire.

Deformation monitoring of landslides is one of the most effective and straightforward methods of geological disaster monitoring, and it is significant for the stability of the landslides. Horizontal displacement versus depth profiles have typically been determined by using traditional inclinometer probes or the strings of downhole inclinometers because of their high accuracy and reliability. Inclinometer probes require the user to measure the slope at $0.6-\mathrm{m}$ intervals within a special grooved pipe. The horizontal displacement must be held constant over a 15-20-min period while the inclinometer measurements are made. When large deformation occurs after landslides, the inclinometer tube should be seriously distorted and deformed, and the inclinometer sensor cannot be sent into the inclinometer tube again. Additionally, strings of downhole inclinometers can be installed at various intervals within an inclinometer pipe. This option is more expensive but allows measurements to be obtained simultaneously and more quickly. Nevertheless, the displacement of the slope must be held relatively constant for several seconds so that the inclinometers can stabilize and provide an accurate reading. This requirement usually precludes their use for dynamic applications. 




Fig. 1 Cross section of the inclinometer tube with a cambered cavity

Generally, the trace of horizontal displacement in the median longitudinal section can be derived based on inclinometer profiles. The system of horizontal displacement monitoring can be illustrated as follows. The inner and outer diameters of the inclinometer tube are respectively 8 and $9 \mathrm{~cm}$, and there is a cambered cavity every $90^{\circ}$. Steel and signal wire can pass through the cavities, as illustrated in Fig. 1. A cross section of the measuring tube is illustrated in Fig. 2. The length, inner diameter, and outer diameter of the measuring tube are respectively $38 \mathrm{~cm}, 20$, and $26 \mathrm{~mm}$. The shape of the three positioned ribbings is a semi-cylinder, with a diameter of $2.5 \mathrm{~mm}$, embedded within the measuring tube. Another positioned ribbing is the combination of a semi-cylinder and an arc, and their diameters are respectively 3 and $1 \mathrm{~mm}$. Segment length is from joint-center to joint-center, as illustrated in Fig. 3. The measuring tubes are installed inside the inclinometer tube via the spring bracket, and every two measuring tubes are connected by the joints, which ensure the continuity of the data acquisition. The thickness and length of the joints are respectively $5 \mathrm{~mm}$ and $8 \mathrm{~cm}$. The joints are pressed by two annular tubes, which can largely increase the tensile strength.

The non-uniform distribution of the positioned ribbing can ensure the unique installation of the MEMS tilt angle sensors. Under the hypothesis that the displacements are uniform not only along the inclinometer vertical but also in each entire cross section of the track, the sliding direction angle is the synthesis of the two directions acquired by the MEMS tilt angle sensor, as shown in Eq. 3.1. Horizontal displacement at different depths can be obtained via the MEMS tilt angle sensor array installed vertically in the measuring tube. Thus, deformation along the depth

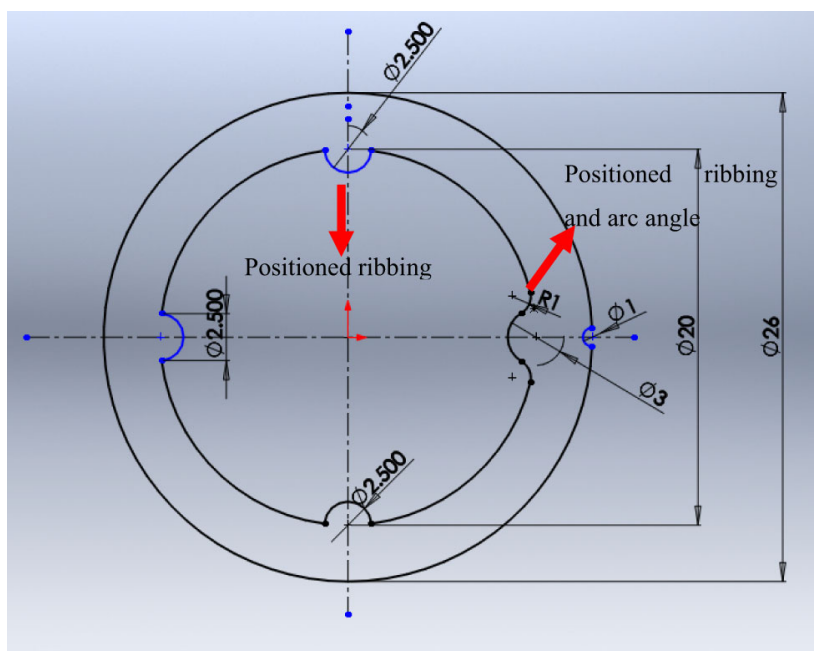

Fig. 2 Cross section of the measuring tube

gradient should be clear after integration along the depth direction, as shown in Eq. 3.2. One data acquisition board is allocated for every eight measuring tubes. The measuring tube does not extend or compress; therefore, it should be oriented perpendicular to the anticipated displacement direction. Measurements are relative to the base point (e.g., stable soil or rock at the end of the borehole).

Simultaneously, the spring bracket installed between the measuring tube and inclinometer tube eliminates the error induced by the guide groove distortion and transmits the deformation from the strata to the MEMS tilt angle sensor inside the measuring tube. The quantity of the spring brackets is based on the length of the measuring tubes. Generally, one spring bracket is advised for every $3 \mathrm{~m}$. There are four cylinders on the edge of the spring bracket, which is connected with the measuring tube and the inclinometer tube via a ball bearing. The structure ensures that the measuring tube is inserted and extracted more easily and reliably. To guarantee the stability and reliability of the measurements, grouting reinforcement is generally used between the inclinometer tube and borehole. This does not influence the use of the spring bracket and the MEMS tilt angle sensor inside the measuring tube.

Herein, two angle components, $\left(\theta_{x}, \theta_{y}\right)$, are respectively defined to express the direction of each segment from the $X$ - and $Y$-axis. This is illustrated in Fig. 4 with a segment length of $500 \mathrm{~mm}$. All the measuring tubes can be seen as straight lines before rotation. Under the hypothesis of the coplanar condition after reversal, the sliding direction and horizontal displacement of each segment can be derived via Eqs. 3.1 and 3.2, wherein $\theta_{x 1}, \theta_{x 2}, \theta_{x 3}$ and $\theta_{y 1}, \theta_{y 2}, \theta_{y 3}$, $\theta_{y 2}, \theta_{y 3}$ represent the angle of different segments. Sliding direction 
Fig. 3 The measuring tube and spring bracket



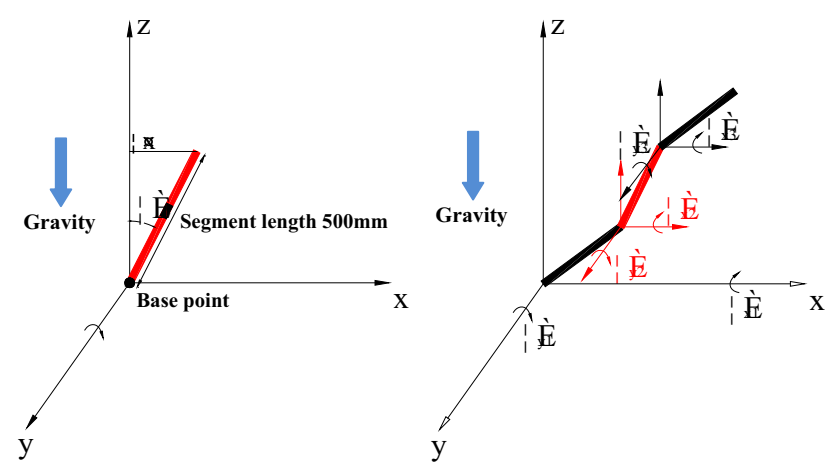

Fig. 4 Measuring principle of horizontal displacement and sliding direction

$\tan \theta_{1}=\frac{\cos \theta_{y 1}}{\cos \theta_{x 1}}=\frac{\cos \theta_{y 2}}{\cos \theta_{x 2}}=\frac{\cos \theta_{y 3}}{\cos \theta_{x 3}}$

Horizontal displacement

$$
\begin{aligned}
\Delta l= & l\left(\sqrt{\cos ^{2} \theta_{x 1}+\cos ^{2} \theta_{y 1}}+\sqrt{\cos ^{2} \theta_{x 2}+\cos ^{2} \theta_{y 2}}\right. \\
& \left.+\sqrt{\cos ^{2} \theta_{x 3}+\cos ^{2} \theta_{y 3}}\right)
\end{aligned}
$$

Depths of the slip surface measurements are transferred to the judgment regarding the on-off state of the signal wire. A sketch map of the measuring principle is illustrated in Fig. 5. An ampere meter is the advised method to transmit the signal to the scientific data loggers. The electrical resistance and sliding rheostat are installed to adjust the value of the electric current to zero at the initial time, and these instruments are all packaged in the scientific data loggers.

To ensure that the signal wire functions normally before the strata dislocation occurs, the signal wire needs to be packaged within an annular tube. Once initial deformation of the slope occurs, the MEMS tilt angle sensor is deflected synchronously to record the angle. When the landslide disaster occurs, the inclinometer tube is first cut off, and the annular tube and the signal wire are subsequently cut off. The cutoff signal is then transmitted to the scientific data loggers. The gear box motor is then activated to lift the signal wire above the slip surface and thereby calculate the length of the signal wire by the angular transducer. Thus, the precise depth measurement of the slip surface can be transferred to the measuring of the on-off state of the signal wire.

High accuracy, large deformation, automation, and recyclable characteristics can be implemented.

A variety of advantages are summarized as follows:

1. Ability to capture the entire landslide process: the system provides horizontal displacement monitoring during the deformation period and deep dislocation displacement monitoring during the shear sliding period.

2. High accuracy: the measuring accuracy of the MEMS sensor is $0.03^{\circ}$, which meets the measurement requirements for landslides.

3. Larger tolerance to shearing: joints installed between two measuring tubes could ensure the monitoring of large deformations, and the combination of an angular displacement sensor with an encoder and steel wire could ensure large deformation monitoring during shear sliding periods.

4. Autonomous data collection: all data acquired from the sensors are transmitted to the data acquisition center via the General Packet Radio Service.

5. Reusable: the measuring tube is connected to the inclinometer tube via a spring bracket, and an antifriction bearing could ensure the reusable characteristics of the measuring tube. 
Fig. 5 Sketch map of the slip surface depth measurement of the landslide

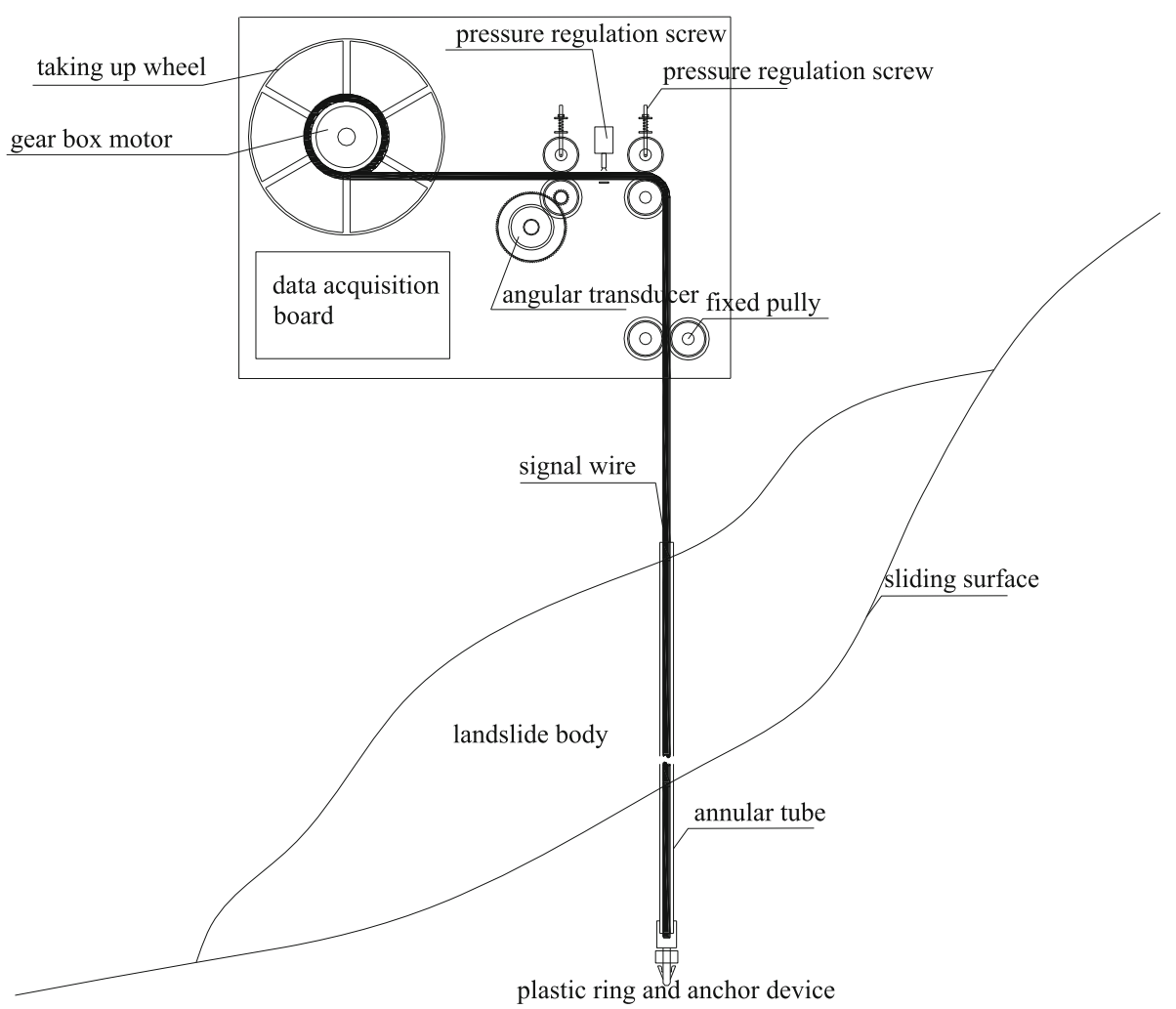

\section{Implementation}

At the beginning of 2015, two horizontal displacement casings, HD1 and HD2, in the Anshan open-pit mine were installed in the slope up to a $15 \mathrm{~m}$ depth. They are installed 157 and $232 \mathrm{~m}$ north from the free face to track the deformation of the slope under the blast loading, as illustrated in Fig. 6. Six MEMS tilt angle sensors were installed in each borehole; the interval of each sensor is $2 \mathrm{~m}$, and the downmost sensor is $2 \mathrm{~m}$ from the bottom of the borehole. In situ installation of inclinometer casings is shown in Fig. 7. The measurement data of HD2-4 and HD2-6 were not obtained because of installation issues. Figure 8 suggests that the greater the distance from the free face of the slope is, the smaller the accumulated horizontal displacement. The figure also indicates that the accumulated horizontal displacement increases with proximity to the surface.

In 2011, two deep dislocation displacement casings, DD1 and DD2, were simultaneously installed up to $45 \mathrm{~m}$ deep at an open-pit mine in Inner Mongolia province. Their positions are illustrated in Fig. 9. Three angular displacement sensors and paired steel wires were installed in each borehole, and the resulting dislocation displacements versus time are illustrated in Fig. 10 with continuous data acquisition. The deep dislocation displacement along the slip surface increased less than $2 \mathrm{~mm}$ in 2 months with an average velocity of $1.0 \mathrm{~mm} / \mathrm{month}$. The rate was ten times
Fig. 6 Sketch map of horizontal displacement monitoring under blast influence

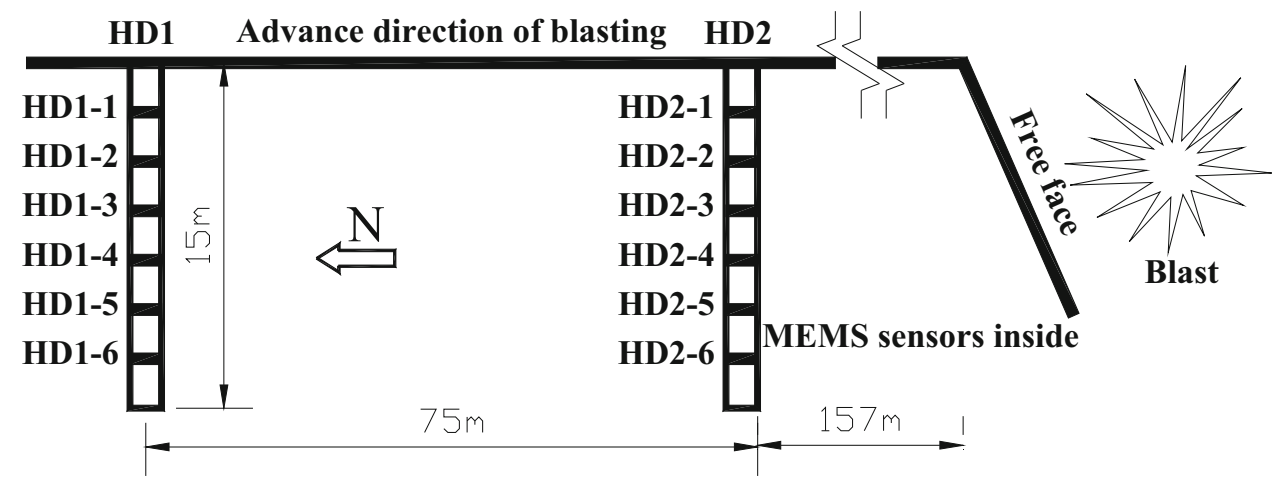


Fig. 7 In situ installation of the deep disloaction displacement instrument
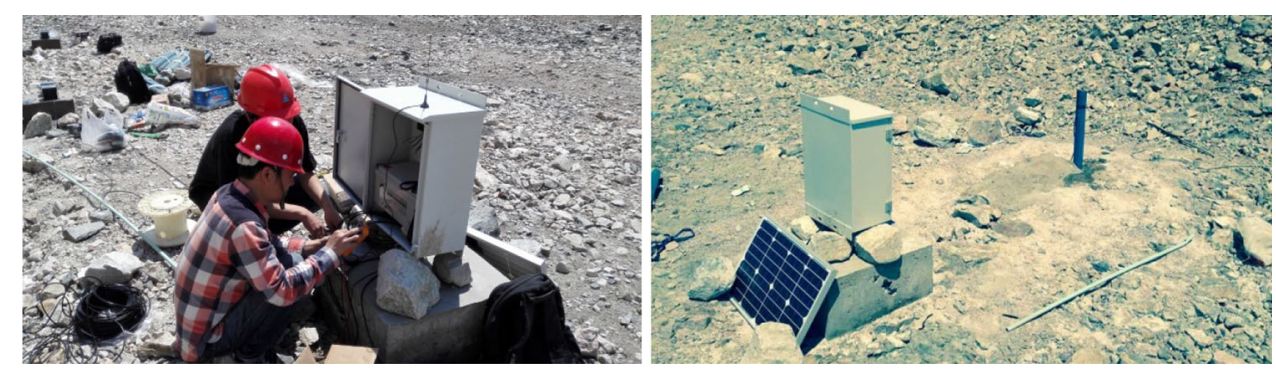

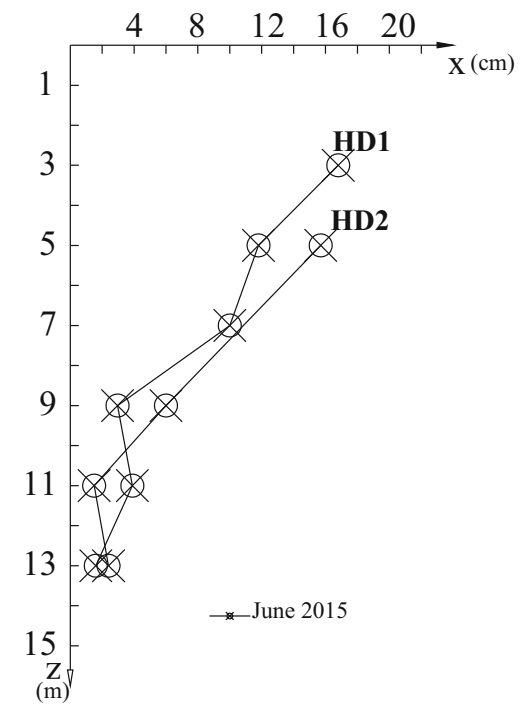

Fig. 8 Curve of cumulative horizontal displacement along with the depth greater than that recorded during a period before June 2011. Internal deformation acceleration appeared on 6 July 2011 and 17 August 2011. From Fig. 10a, we could observe that the swift increase in displacement occurred on 30 August 2011. Simultaneously, two probable sliding planes are identified by the relationships between the blue line, red line, and black line. One sliding plane is above $18 \mathrm{~m}$, and the other sliding plane is between 37 and $40 \mathrm{~m}$. Another sliding plane could be recognized above $15 \mathrm{~m}$ via Fig. 10b. Thus, we could infer that the sliding plane was above $15 \mathrm{~m}$. Based on the investigation after the landslide, the depth of the sliding plane was determined to be $14.5 \mathrm{~m}$.

The $\mathrm{Yu}$ Jiaba landslide is located at the middle of Gangkou town, Wulong County, Chongqing province. This area belongs to the emergency project of the Third Geological Disaster Prevention Engineering project for the Three Gorges Reservoir. It is a soil and rock mixture deposit, mainly consisting of fine grains, sands, gravels,
Fig. 9 The locations of DD1 and DD2 at the open-pit mine

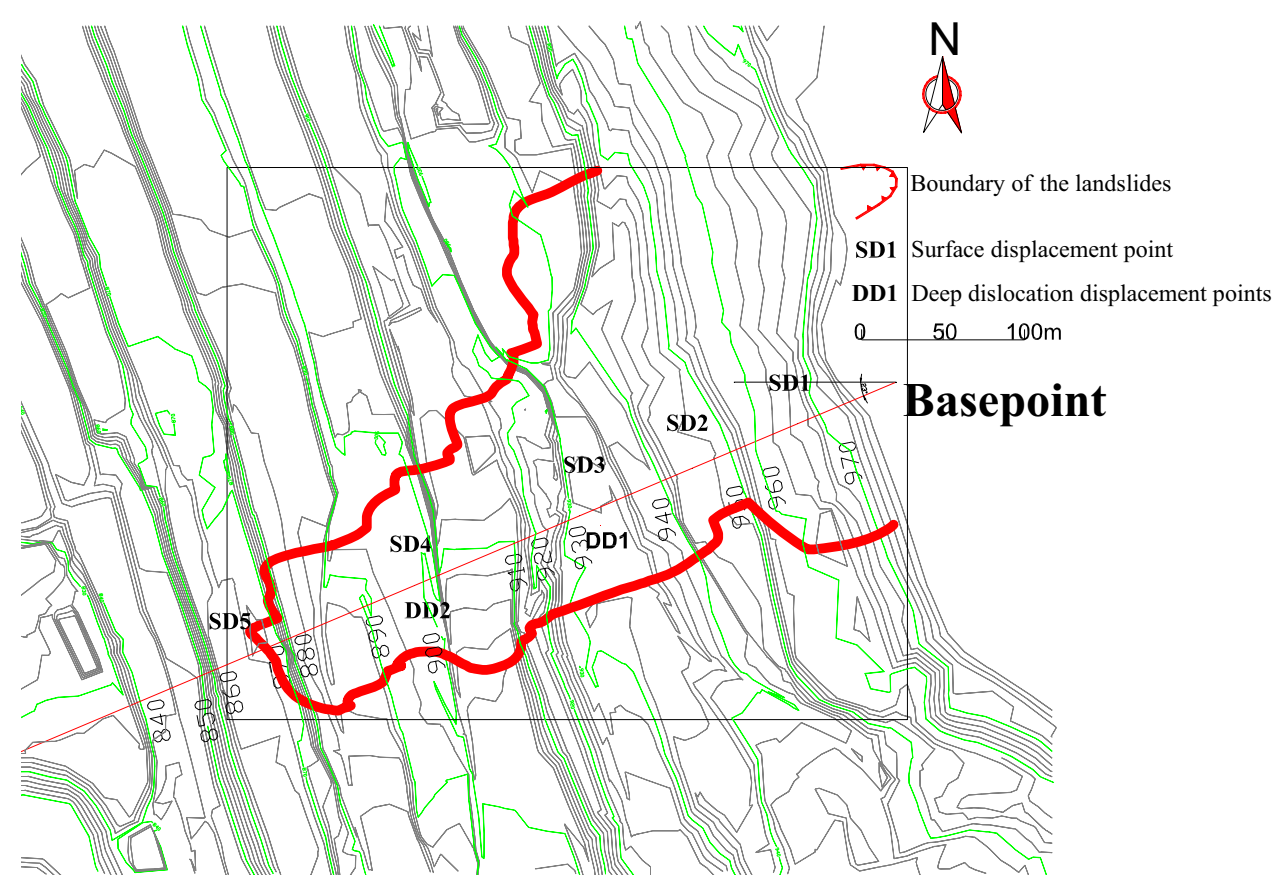





Fig. 10 Deep dislocation displacement curve over time (open-pit mine in Inner Mongolia province). a DD1, b DD2


Fig. 11 Deep dislocation displacement curve over time (Yu Jiaba landslide in Chonqing Province). a DD3, b DD4

cobbles, and boulders. Two deep dislocation displacement casings (DD3 and DD4) were installed here in 2009. The depths of the boreholes are respectively 30 and $20 \mathrm{~m}$, the base point is within the bedrock surface at approximately 3-5 $\mathrm{m}$, and three measuring points are 2-m intervals upwards from the base point. Three angular displacement sensors and paired steel wires were installed in each borehole. Continuous data acquisition lasted for 4 years (Fig. 11). The maximum cumulative displacement over 4 years was only $3-6 \mathrm{~mm}$, and the stability time lasted nearly for 2 years. The magnitude of DD3 is less than that of DD4 because the depth of the measuring point is different. Meanwhile, the deformation starting time of DD3 is later than that of DD4. These conclusions are all reasonable. This project aims to demonstrate the stability of the instrument and reliability of data transmission.
The automated sensors have captured data at both sites, which are of significant value in characterizing the slope behavior and providing an early warning system to ensure the safety of open-pit mines.

\section{Discussion}

The real-time monitoring instrument, as demonstrated, adapts perfectly to the periodic or continuous monitoring of colluvial landslides. This monitoring instrument is able to provide an adequately reliable predictive capability with respect to preliminary failure forecasting and emergency management. From the three briefly illustrated cases, a real-time monitoring instrument can evidently be employed advantageously. It should be pointed out that the 
instrumentation used in the study of landslides is a powerful investigative tool, but in no case should it be the aim of research. Nevertheless, the significance of the deep dislocation displacement or sliding direction needs to be discussed to correctly use them as failure predictors.

Deep dislocation displacement and horizontal displacement measurings are point measuring with different depths. Generally, multi-point measuring should be implemented at different elevations along the longitudinal section of colluvial landslides. Even so, only limited measuring data could be acquired. Thus, the selection of the longitudinal section is crucial. The instrument should be applied together with radar monitoring; thus, the behavior or characteristics of colluvial landslides will eventually be attained.

The instrument is designed for monitoring colluvial landslides. The base point is embedded in the bedrock, and the measuring point is above the slip surface, so the depth of the borehole theoretically exceeds the depth of the bedrock. The horizontal displacement monitoring by MEMS sensors enables displacement profiles to be determined with high accuracy and precision (up to $\pm 0.03^{\circ}$, equivalent to $\pm 0.5 \mathrm{~mm} / \mathrm{m}$ ) and has a maximum measuring range of $90^{\circ}$. For example, for a 50-m-deep borehole, the cumulative error of horizontal displacement close to the surface will reach $2.6 \mathrm{~cm}$; as we all know, the displacement occurring at the surface of the colluvial landslides is much larger than that occurring underground. The accuracy of deep dislocation displacement measurement is $0.1 \mathrm{~mm}$, and the measuring range includes 1,3 , and $5 \mathrm{~m}$. The accuracy and measuring range perfectly meet the demand of large deformation measurement for colluvial landslides. The depth of the slip surface can be calculated by the angular transducer with an encoder, and the accuracy is $1 \mathrm{~mm}$. The sliding direction angle is the synthesis of the two directions acquired by the MEMS tilt angle sensor, so the accuracy of the angle is consistent with the abovediscussed horizontal displacement.

\section{Conclusions}

The originality of this study lies in the development of a new real-time monitoring instrument to track the landslide body, which can capture horizontal displacement, deep dislocation displacement, accurate depth of the slip surface, and sliding direction. The real-time monitoring during the deformation period and the initial sliding period can be executed via this one instrument. Simultaneously, high accuracy, large deformation capability, automation, and recyclable characteristics are implemented. In summary, some of the conclusions are as follows:
1. Horizontal displacement at different depths can be obtained by an MEMS tilt angle sensor array installed vertically in the measuring tube, and deformation with depth could thereby be obtained after integration along the depth direction. Deep dislocation displacement of the slip surface can be obtained from the length of steel wire pulled along the sliding direction, and the length variation would be captured by the angular displacement sensor at the top of the inclinometer tube. Depth of the slip surface measuring is transferred to a judgment regarding the on-off state of the signal wire, which can be calculated by the angular transducer with an encoder. The sliding direction angle is the synthesis of the two directions obtained by the MEMS tilt angle sensor.

2. Based on long-term monitoring and the information obtained by the new inclinometers and deep dislocation casings, cumulative horizontal displacement along the depth gradient under conditions of blast influence has been obtained. These measurements accurately reflect the behavior of the slope under explosion loads. Displacement rates of the landslide in open-pit mines were up to $1 \mathrm{~mm} /$ month at the lower level before rainy periods, with a swift increase after rainstorms on 31 August 2011. Under such circumstances, the deep dislocation casings have been revealed as a very useful tool for monitoring.

Acknowledgments The author would like to sincerely thank S.W. Yang and L.K. Xu for their structure and data acquisition designs. The work presented in this paper was supported by the National Natural Science Foundation of China (11302229), the 973 Program (2015CB250903), and the Chinese Academy of Sciences Special Fund for strategic pilot technology (XDB10030303). The authors are grateful for the support.

\section{References}

Allaway A, Merrett PJ, Eyre JM, Stead D (1998) The application of GPS in monitoring landslide movements. In Proc. of 8th Int. IAEG Congress, Balkema, Rotterdam, pp 1633-1640

Alves FS, Dias RA, Cabral J, Rocha LA (2012) Pull-in MEMS inclinometer. Procedia Eng 47:1239-1242

Angeli MG, Pasuto A, Silvano S (2000) A critical review of landslide monitoring experiences. Eng Geol 55(3):133-147

Ashkenazi V, Dodson AH, Sykes RM, Crane SA (1980) Remote measurement of ground movements by surveying techniques. Civil Eng Surv 5(4):15-22

Ballantyne JD, Dean Jr DR, Thompson BL (1988) Monitoring landslide movement with a 35-mm camera. Transport Res Rec 1119:47-54

Chandler JH, Moore R (1989) Analytical photogrammetry: a method for monitoring slope instability. Q J Eng GeolHydrogeol 22(2):97-110

Coe JA, Godt JW, Ellis WL, Savage WZ, Savage JE, Powers PS, Tachker P (2000) Preliminary interpretation of seasonal 
movement of the Slumgullion landslide as determined from GPS observations, July 1998-1999. USGS Open-File Report, 00-102

Colesanti C, Ferretti A, Prati C, Rocca F (2003) Monitoring landslides and tectonic motions with the permanent scatterers technique. Eng Geol 68(1):3-14

Crosta G, Agliardi F (2003) Failure forecast for large rock slides by surface displacement measurements. Can Geotech J 40(1):176-191

Di Maio C, Vassallo R, Vallario M (2013) Plastic and viscous shear displacements of a deep and very slow landslide in stiff clay formation. Eng Geol 162:53-66

Dick GJ, Eberhardt E, Cabrejo-Liévano AG, Stead D, Rose ND (2014) Development of an early-warning time-of-failure analysis methodology for open-pit mine slopes utilizing ground-based slope stability radar monitoring data. Can Geotech J 52(4):515-529

Gili JA, Corominas J, Rius J (2000) Using global positioning system techniques in landslide monitoring. Eng Geol 55(3):167-192

Gulla G, Nicoletti PG, Sorriso-Vavo M (1988) A portable device for measuring displacements along fractures. Proceedings of the 5th International Synposium on landslides, Lausanne, Balkema, 1, $423-426$

Hu X, Zhang M, Sun M, Huang K, Song Y (2015) Deformation characteristics and failure mode of the Zhujiadian landslide in the Three Gorges Reservoir, China. Bull Eng Geol Environ 74(1):1-12

Keaton JR, DeGraff JV (1996) Surface observation and geologic mapping. Landslides, Investigation and Mitigation, Transportation Research Board, National Research Council Special Report, 247, 11

Kopf A, Freudenthal T, Ratmeyer V, Bergenthal M, Lange M, Fleischmann T, Wefer G (2015) Simple, affordable, and sustainable borehole observatories for complex monitoring objectives. Geosci Instrum Methods Data Sys 4(1):99-109

Krauter E (1988) Applicability and usefulness of field measurements on unstable slopes. In Proceedings of the 5th international symposium on landslides, Lausanne, pp 367-373)

Lan HX, Zhou CH, Wang LJ, Zhang HY, Li RH (2004) Land slide hazard spatial analysis and prediction using GIS in the Xiaojiang watershed, Yunnan, China. Eng Geol 76(1):109-128
Liu DA, Yang ZF, Tang CH, Wang J, Liu Y (2004) An automatic monitoring system for the shiplock slope of Wuqiangxi Hydropower Station. Eng Geol 76(1):79-91

Meng XY, Li SH, Wang XK (2007) The device about measuring the depth of slip surface and deep dislocation displacement, (Publication Number: CN2854507 Y), patent issued in 2007

Mikkelsen PE (1996) Field instrumentation. In: Turner AK, Schuster RL (eds) Landslides Investigation and Mitigation, TRB Special Report 247. National Academy Press, Washington, pp 278-316 (Chapter 11)

Oka N (1998) Application of photogrammetry to the field observation of failed slopes. Eng Geol 50(1):85-100

Pincent B, Blondeau F (1978) Detection et suivi des glissements de terrain. In Proceedings of the 3rd international congress IAEG, Madrid (vol 1, no. 1, pp 252-266)

Schuster RL, Krizek R (1978) Landslides: analysis and control, TRB Special Report 176. National Academy Press, Washington

Tang H, Li C, Hu X, Wang L, Criss R, Su A, Xiong C (2015) Deformation response of the Huangtupo landslide to rainfall and the changing levels of the Three Gorges Reservoir. Bull Eng Geol Env 74:933-942

Tarchi D, Casagli N, Fanti R, Leva DD, Luzi G, Pasuto A, Silvano S (2003) Landslide monitoring by using ground-based SAR interferometry: an example of application to the Tessina landslide in Italy. Eng Geol 68(1):15-30

Tuccimei P, Mollo S, Soligo M, Scarlato P, Castelluccio M, Kopf A, Fleischmann $\mathrm{T}$ (2015) Real-time setup to measure radon emission during rock deformation: implications for geochemical surveillance. Geosci Instrum Method Data Syst. 4:111-119

Ulusay R (ed) (2015) The ISRM suggested methods for rock characterization, testing and monitoring: 2007-2014. International Society for Rock Mechanics, Commission on Testing Methods

Yin Y, Wang H, Gao Y, Li X (2010) Real-time monitoring and early warning of landslides at relocated Wushan Town, the Three Gorges Reservoir, China. Landslides 7(3):339-349

Zhao B, Xu WY, Meng YD, Liang GL (2015) Security monitoring of a large-scale and complex accumulation slope: an application in the Xiluodu hydropower station. Bull Eng Geol Environ 74(2):327-335 